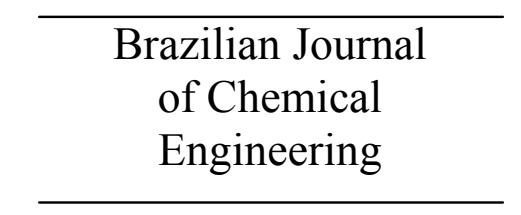

ISSN 0104-6632

Printed in Brazil

www.abeq.org.br/bjche

Vol. 27, No. 04, pp. 555 - 562, October - December, 2010

\title{
DESCRIPTION OF CONSOLIDATION FORCES ON NANOMETRIC POWDERS
}

\author{
D. Turki ${ }^{1 *}$ and N. Fatah ${ }^{2}$ \\ ${ }^{1}$ Université Ibn-Khaldoun de Tiaret, Faculté des sciences et science de l'ingénieur, \\ BP 78, 14000 Tiaret, Algeria. \\ *E-mail: turkidjamel@yahoo.fr \\ ${ }^{2}$ Unité de Catalyse et de Chimie du Solide, UMR CNRS 8181, ENSC Lille, \\ bat. C7, 59655, Villeneuve d'Ascq Cedex, France. \\ E-mail: nouria.fatah@ec-lille.fr
}

(Submitted: June 28, 2009 ; Revised: December 28, 2009 ; Accepted: April 28, 2010)

\begin{abstract}
The experiments and analyses performed included measurements of the physical properties of $\mathrm{TiO}_{2}$ powder such as the particle size, density, and consolidation. Experiments with nanometric $\mathrm{TiO}_{2}$ powder of $204 \mathrm{~nm}$ average diameter show that, during consolidation, the adhesion of particles under normal stress is principally due to the van der Waals force for particle radii less than $300 \mathrm{~nm}$ and the application of external force has no effect on the cohesion of the primary particles within this range; for particle radii around 300nm to $1.0 \mu \mathrm{m}$ the cohesion of the powder system is due to plastic deformation and the application of external force change the cohesion force to a plastic deformation between the agglomerates formed under these forces. This can be observed in the arrangement of the primary particles into dispersed agglomerates with sizes greater than the individual particles. The results obtained with the nanometric $\mathrm{TiO}_{2}$ powders show a more complex behavior than the micronic powders. This behavior is related to the structure of the nanometric particles in the packed bed; the evolution of this structure is made up of individualized and spherical agglomerate shapes. It has been experimentally observed that the powder structure is not perturbed by stresses of low intensities. A development of the different forces involved in interparticle contacts is outlined. The description of these forces involved in particle cohesion will help to understand the powder cohesion under consolidation. Keywords: Consolidation; Interparticle forces; Nanometric powder; van der Waals forces.
\end{abstract}

\section{INTRODUCTION}

The micronic and nanometric group $\mathrm{C}$ powders are very complex to handle and store (Geldart, 1973); this is principally due to the great cohesion between particles. The cohesive powders tend to form agglomerates of completely random size and shape by the action of the interparticle forces between the primary particles. These forces control the particulate system and govern the behavior of a bed composed of fine particles. In practice, it has been noticed that this cohesive structure evolves under the influence of external stress. The volume of the structure is reduced when the normal stress is increased. Consequently, the solid structure and the powder behavior are affected. This phenomenon is often encountered in the consolidation of powders, as in the case of storage of solid.

Medhe et al. (2005) tried to explain the consolidation effect on the basis of particle mechanic theories related to elastic-plastic deformation behavior. The flow of powder is generally characterized by using shear strength testers where the powders under these conditions endure a compressive load (MorenoAntanasio et al., 2005).

The consolidation of the cohesive powder is related to the surface properties and the area of deformation of particles in contact. This deformation

*To whom correspondence should be addressed 
is characterized by an enhancement of contact area (Götzinger and Peukert, 2003). The consolidation of micronic particles is the basis of different parameters where external forces and the interparticle forces are the predominant features (Castellanos, 2005).

Valverde and Castellanos (2007) showed that an increase in consolidation stress results in the formation of disordered agglomerates, leading to a reduction in internal porosity within the packed agglomerates. As outlined by Quintanilla et al. (2001), cohesive powders are generally consolidated by the application of external forces causing an increase in the interparticle adhesion forces. Vermeer et al. (2001) showed that the behavior of cohesive powders is related to the adhesive and the compressive forces.

Molerus (1975) explained that the adhesion forces are more significant in a consolidated system and the plastic deformation is the reason for particle cohesion in the developed model.

The aim of this work is to study the variation of the cohesive powder structure under the action of the interparticle forces (van der Waals forces) and an external stress (consolidation). This study can help to understand the deformation of the powder structure and the real cause that incites the cohesion of particles. A general description of all forces (van der Waals, elastic and plastic) involved in particle interaction is established to show the real cause of particle cohesion. Different measurements techniques have been used to understand the behavior of fine particles (Turki and Fatah, 2008). The experiments and analyses performed included measurements of the physical properties of the powder such as the particle size, density and solid fraction (test of consolidation).

\section{A MODEL DESCRIBING THE ADHESION FORCE WITHIN PACKED PARTICLES}

Interparticle forces may be the origin of the contact surface deformation (Fichman and Pnueli, 1985) and a good estimation of contact forces may help to overcome powder flow problems (Quintanilla et al., 2006). Consequently, the adhesion force can be related to the applied compressive force (consolidation). The behavior of cohesive powders is determined by the interaction between external forces and cohesion forces (Molerus, 1975).

When the system is consolidated, there is equilibrium between the normal force $(F)$ due to external stress, the attraction force due to the van der Waals force $\left(\mathrm{F}_{\mathrm{VdW}}\right)$ and the elastic or plastic force of the solid $\left(\mathrm{F}_{\mathrm{s}}\right)$, as developed by Molerus (1975):

$$
\mathrm{F}+\mathrm{F}_{\mathrm{VdW}}=\mathrm{F}_{\mathrm{s}}
$$

Hamaker (1937) used the additivity law proposed by London (1937) to determine the equations for the van der Waals forces between particles.

The energy $(\mathrm{W})$ of interaction between particles 1 and 2 of volumes $\mathrm{v}_{1}$ and $\mathrm{v}_{2}$ containing $\mathrm{q}_{1}$ and $\mathrm{q}_{2}$ atoms per $\mathrm{cm}^{3}$ is:

$\mathrm{W}=-\int_{\mathrm{v}_{2}} \mathrm{dv}_{1} \int_{\mathrm{v}_{2}} \mathrm{dv}_{2} \frac{\mathrm{q}_{1} \mathrm{q}_{2} \lambda_{1,2}}{\mathrm{Z}^{6}}$

where $\lambda_{1,2}$ is a constant depending on the molecular characteristics and $\mathrm{Z}$ is the distance between the center points of two molecules.

The additivity law presented by Hamaker (1937) calculates the force based on the interaction between individual atoms making up the particles.

The van der Waals force is given by:

$\mathrm{F}_{\mathrm{vdW}}=\frac{\partial \mathrm{W}}{\partial \mathrm{z}}$

The integration of Equation (2) performed by Bradely (1932) and Hamaker (1937) gives the total attractive energy $\mathrm{W}$ between two particles without deformation:

$\mathrm{W}=-\frac{\mathrm{AD}}{12 \mathrm{z}}$

where A is the Hamaker constant, D is the reduced diameter of the particles and $\mathrm{z}$ is the distance between the two particles.

The interaction of two particles is achieved by the flattening of the particles' extremities with $\varphi$ as the surface of the flattened region where deformation occurs. The integration of Equation (2) presented by Xie (1997) gives:

$$
\mathrm{W}=-\frac{\mathrm{AD}}{12 \mathrm{z}}\left[1+\frac{\mathrm{a}^{2}}{2 \mathrm{Dz}}\right]
$$

where a is the radius of the flattened contact surface $(\varphi)$ and $\mathrm{A}$ is the Hamaker constant according to Israelachvili (1991). This constant is evaluated when the medium is the vacuum by: 
$\mathrm{A}=\frac{3 \mathrm{~B} \mathrm{~T}}{4}\left(\frac{\varepsilon_{1}-1}{\varepsilon_{1}+1}\right)^{2}+\frac{3 \mathrm{~h} v_{\mathrm{c}}}{16 \sqrt{2}} \frac{\left(\mathrm{N}_{1}^{2}-1\right)^{2}}{\left(\mathrm{~N}_{1}^{2}+1\right)^{1.5}}$

where $\mathrm{B}, \mathrm{T}, \varepsilon_{1}, \mathrm{~h}, \mathrm{v}_{\mathrm{c}}$ and $\mathrm{N}_{1}$ are Boltzmann's constant, the temperature, the dielectric constant, the Planck's constant, the UV adsorptive frequency, and the index of refraction, respectively.

The differentiation of Equation (5) leads to the van der Waals force between two spherical particles:

$\mathrm{F}_{\mathrm{VdW}}=\frac{\partial \mathrm{W}}{\partial \mathrm{z}}=\frac{\mathrm{AD}}{12 \mathrm{z}^{2}}\left[1+\frac{\pi \mathrm{a}^{2}}{\pi \mathrm{Dz}}\right]=\frac{\mathrm{AD}}{12 \mathrm{z}^{2}}\left[1+\frac{\varphi}{\pi \mathrm{Dz}}\right]$

where $\varphi$ is the contact surface $\left(\varphi=\pi \mathrm{a}^{2}\right)$.

When two particles are in contact and following the assumption of Hertz (1985), i.e., purely elastic deformation, according to JKR theory (Johnson et al., 1971), the radius of the flattened contact surface $(\varphi)$ under no load is given by:

$\mathrm{a}^{3}=\frac{3 \mathrm{~F}_{\mathrm{s}} \mathrm{R}}{\mathrm{K}}$

where Fs is the contact force between particles, $\mathrm{R}$ is the particle radius and $\mathrm{K}$ is given by the following expression according to Christenson (1996):

$$
\mathrm{K}=\frac{2}{3} \frac{\mathrm{E}}{\left(1-v^{2}\right)}
$$

where E represents the Young's modulus and $v$ corresponds to the Poisson ratio. The contact area of deformation can be expressed as:

$$
\varphi=\pi .\left[\frac{3 \mathrm{~F}_{\mathrm{S}} \mathrm{R}}{\mathrm{K}}\right]^{2 / 3}
$$

The normal pressure $\mathrm{p}$ over the projected area of deformation is:

$\mathrm{p}=\frac{\mathrm{F}_{\mathrm{S}}}{\varphi}$

Substituting Equation (9) into Equation (10) leads to:

$$
\mathrm{p}=\frac{\mathrm{F}_{\mathrm{s}}^{1 / 3} \mathrm{~K}^{2 / 3}}{3^{2 / 3} \pi \mathrm{R}^{2 / 3}}
$$

It was shown by Tabor (1951) that elastic deformation takes place when:

$\mathrm{p}=1.1 \sigma_{\mathrm{y}}$

where $\sigma_{y}$ is the stress rupture of the material. Inserting expression (12) in (11) leads to the relation for the limit of the elastic deformation, $F_{\text {elastic, the }}$ force at which the elastic deformation occurs $\left(\mathrm{F}_{\mathrm{s}}=\right.$ $\left.\mathrm{F}_{\text {elastic }}\right)$ :

$\mathrm{F}_{\text {elastic }}=\frac{371.4 \sigma_{\mathrm{y}}^{3} \mathrm{R}^{2}}{\mathrm{~K}^{2}}$

In a normal situation, apart from the van der Waals force and the elastic force, an external force (F) is added in the adhesion. When no external compressive force is applied on the powder, the system may follow an elastic deformation with van der Waals interaction. Subsequently, it follows that, during consolidation, a plastic deformation is engendered.

When the external force is applied on the powder, the force is further increased to reach a plastic deformation. It was shown by Tabor (1951) that plastic deformation takes place when:

$\mathrm{p}=3 \sigma_{\mathrm{y}}$

Therefore, substituting (14) in (11) leads to:

$\mathrm{F}_{\text {plastic }}=\frac{7534.5 \sigma_{\mathrm{y}}^{3} \mathrm{R}^{2}}{\mathrm{~K}^{2}}$

where $F_{\text {plastic }}$ is the force at which the plastic deformation takes place $\left(\mathrm{F}_{\mathrm{s}}=\mathrm{F}_{\text {plastic }}\right)$.

\section{MATERIALS AND METHODS}

\section{Particle Size Distribution}

In this work $\mathrm{TiO}_{2}$ powder of the Kronos company was studied: Anatase $\left(99 \%\right.$ of $\left.\mathrm{TiO}_{2}\right)$. The powder size distribution was measured with a laser lightscattering instrument (Beckman-Coulter, LS230). This experiment measures the particle size. The average diameter of the $\mathrm{TiO}_{2}$ powder was calculated according to the diameter definition "surfacevolume" or Sauter diameter: 


$$
\mathrm{d}_{\mathrm{p}}=\frac{\sum \mathrm{N}_{\mathrm{i}} \mathrm{d}_{\mathrm{i}}^{3}}{\sum \mathrm{N}_{\mathrm{i}} \mathrm{d}_{\mathrm{i}}^{2}}
$$

where $\mathrm{N}_{\mathrm{i}}$ is the number of particles in class $\mathrm{i}$ and $\mathrm{d}_{\mathrm{i}}$ the average diameter of the particle in this class.

The range of the particle size distribution was quantified using the index of uniformity $\mathrm{C}_{\mathrm{u}}$ (Schlosser, 1998) obtained from the cumulative percentage undersize curve (in volume) and defined by the following equation:

$$
\mathrm{C}_{\mathrm{u}}=\frac{\mathrm{d}_{\mathrm{i} 60 \%}}{\mathrm{~d}_{\mathrm{i} 10 \%}}
$$

$\mathrm{C}_{\mathrm{u}}<2$ : The particle size distribution is known as uniform.

$\mathrm{C}_{\mathrm{u}}>2$ : The particle size distribution is known as non-uniform or broad.

$\mathrm{d}_{\mathrm{i} 60 \%}$ and $\mathrm{d}_{\mathrm{i} 10 \%}$ are defined as dimensions of the particles corresponding, respectively, to $60 \%$ and $10 \%$ of the particle size distribution of the cumulative curve.

The density $\left(\rho_{\mathrm{p}}\right)$ of the $\mathrm{TiO}_{2}$ particles was measured with a helium gas pycnometer (Micromeritics, AccuPyc 1330).

\section{Consolidation Test}

The consolidation test shows the aptitude that a powder has to consolidate, i.e., to decrease the volume of the packed bed of powder under the effect of an increasing normal stress $(\sigma)$. A known mass of powder (M) is introduced into a graduated glass cylinder of $5.3 \mathrm{~cm}$ in diameter. The base of the cylinder is closed by a porous plate to allow the evacuation of the air stored in the powder during consolidation. A twister is introduced into the cylinder to homogenize the surface of the powder. A hollow glass cylinder of $5.1 \mathrm{~cm}$ in outer diameter closed at both ends that acts as a weight support is applied on the powder bed. Thus, the variation of the packed bed volume is measured according to the force $\left(F_{N}\right)$. The solid fraction $(1-\varepsilon)$ related to the normal stress $(\sigma)$ is noted as:

$$
1-\varepsilon=\frac{M}{\rho_{P} V_{t}}
$$

$\mathrm{M}$ and $\mathrm{V}_{\mathrm{t}}$ are the mass and the total volume of the packed bed of particles, respectively. The normal stress is given by

$\sigma=\frac{F_{N}}{S}$

where $F_{N}$ is the applied force on the powder structure and $\mathrm{S}$ is the cross-sectional area of the glass support.

During the consolidation test, it is important to note that the application of different stresses on the $\mathrm{TiO}_{2}$ powder has the role of consolidating the powder without breaking or fracturing the particles; however, it is extremely difficult to break particles of sizes less than a micrometer.

\section{RESULTS AND DISCUSSION}

In this present work we have tried to analyze the evolution of a nanometric powder according to the external forces (consolidation) by comparing the different forces acting between particles. The particle size distribution of the $\mathrm{TiO}_{2}$ powder is obtained according to an optimal procedure of dispersion in order to measure the size of the primary particles and not that of agglomerates. The particle size distribution of the $\mathrm{TiO}_{2}$ powder is given in Figure 1. The average size of the particles is $d_{p}=204$ $\mathrm{nm}$. The $\mathrm{C}_{\mathrm{u}}$ index is obtained from the cumulative percentage curve and defined by Equation (17). This parameter indicates a broad size distribution corresponding to $\mathrm{C}_{\mathrm{u}}=3.6$. In spite of the optimal protocol of dispersion, we think that this large interval is due to the presence of agglomerates, as shown in Figure 1. A first peak around $225 \mathrm{~nm}$ is observed that seems rather close to the average diameter calculated. The particle density $\left(\rho_{\mathrm{p}}\right)$ is 3900 $\mathrm{kg} / \mathrm{m}^{3}$.

Figure 2 shows the variation of the solid fraction (1- $\varepsilon$ ) according to the normal stress $(\sigma)$ (test of consolidation). In the initial state, a high rate of aeration is noted, indicating a solid fraction of about $15 \%$ for $\mathrm{TiO}_{2}$ powder. This behavior is related to a heterogeneous structure formed by heaped agglomerates. Then, for a low consolidation, (1- $\varepsilon)$ increases with $\sigma$ to a slightly linear evolution. This corresponds to the diffusion of air in the structure of the packed bed formed by agglomerates. For higher values of $\sigma$, the transition zone is reached, corresponding to the load supported by the solid structure; then packing and rearrangement of the particles occurs. Beyond this zone, the load is spread out on the solid; thus, there is consolidation of the packed bed of powder. 


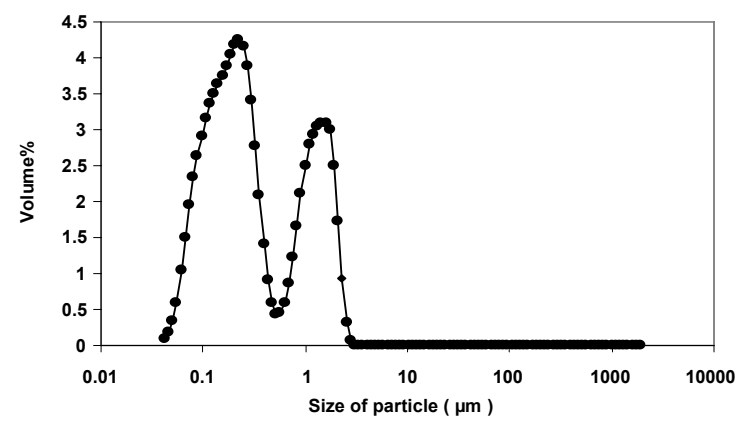

Figure 1: Particle size distribution of $\mathrm{TiO}_{2}$

It seems important in this study to estimate the applied stress $\sigma_{\mathrm{p}}$ on every particle. Rumpf (1962) developed a simple relation between $\sigma_{\mathrm{p}}$ and the external force F applied on the particle. Supposing that the particles are spherical and the structure of the bed is homogeneous, then the relation of Rumpf is given by:

$$
\sigma_{\mathrm{p}}=\frac{\mathrm{F} \cdot(1-\varepsilon) \cdot \mathrm{j}_{\mathrm{i}}}{\mathrm{s}_{\mathrm{p}}}
$$

where $\varepsilon$ and $s_{p}$ are the bed voidage and the particle surface, respectively.

According to Nakagaki (1968), the coordination number $\mathrm{j}_{\mathrm{i}}$ i.e., the statistical mean number of contact of one particle with adjacent ones is given by:

$\mathrm{j}_{\mathrm{i}}=1.61 . \varepsilon^{-1.48}(\varepsilon \leq 0.82)$

In this work, $\mathrm{F}$ is deduced from the normal stress $(\sigma)$ applied on the packed bed of particles used in the test of consolidation and the surface of the particle $\mathrm{s}_{\mathrm{p}}$.

$\mathrm{F}=\sigma . \mathrm{s}_{\mathrm{p}}$

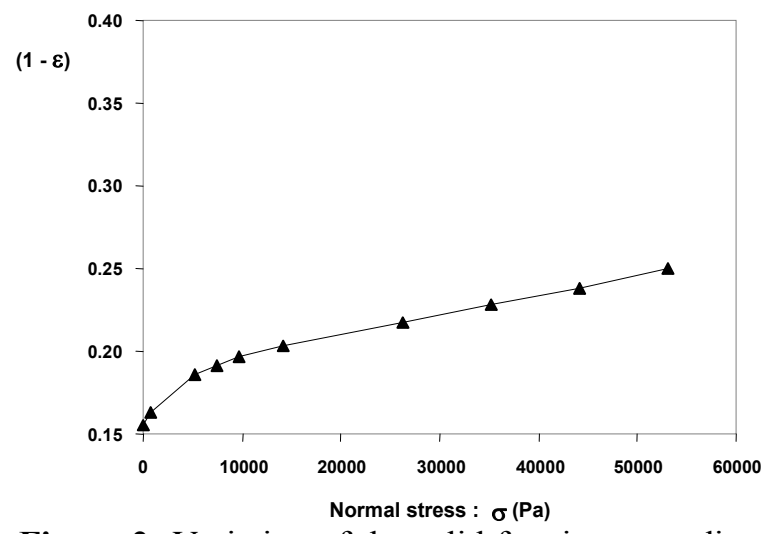

Figure 2: Variation of the solid fraction according to the normal stress for the $\mathrm{TiO}_{2}$ powder

Therefore, substituting Equations (21) and (22) in (20) leads to:

$\sigma_{\mathrm{p}}=\frac{1.61 \sigma(1-\varepsilon)}{\varepsilon^{1.48}}$

Figure 3 illustrates the normal stress $(\sigma)$ applied on the bed of powder (test of consolidation) and the particle-particle interaction stress $\left(\sigma_{\mathrm{p}}\right)$ according to the variation of the solid fraction. The particle-particle interaction $\left(\sigma_{p}\right)$ is less significant for a stress with a low value and with a solid fraction $(1-\varepsilon)<0.19$. This region corresponds to the diffusion of air stored in the solid structure under normal stress $(\sigma)$. Beyond this zone, $\sigma_{p}$ increases with respect to the solid fraction $(1-\varepsilon)$ and the normal stress $(\sigma)$. This reflects the behavior of the cohesive powders under the effect of consolidation. These results in breaking up of agglomerates by bringing the primary particles closer, where the interparticle forces (van der Waals) are important, inducing the solid structure to a high degree of cohesion. Moreover, the cohesive structure via particleparticle contact causes a significant deformation that is the basis of the plastic or elastic force.

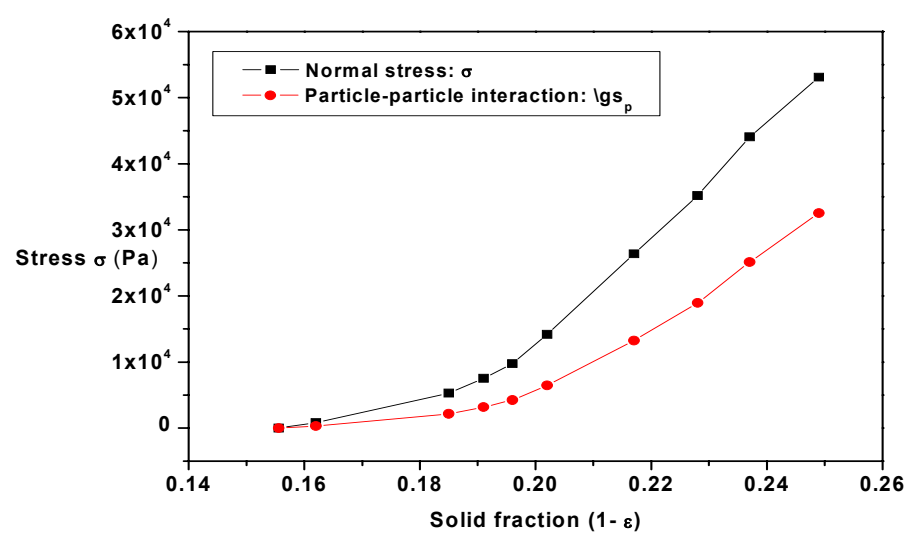

Figure 3: Comparison of the normal stress $(\sigma)$ and normal stress particle-particle interaction $\left(\sigma_{\mathrm{p}}\right)$ 
To understand the impact of the van der Waals forces compared to the elastic and plastic forces, the values of the three forces are evaluated from Equations (7), (13) and (15), respectively.

The calculations of these forces are carried out without consolidation effects and assuming that the particles are spherical and smooth.

The parameters: $\mathrm{N}_{1}, \varepsilon_{1}, v_{\mathrm{c}}, \mathrm{B}$ and $\mathrm{h}$ in Equation (6) are obtained from Perry and Green (1984) and Israelachvili (1991). The index of refraction $\left(\mathrm{N}_{1}\right)$ and the dielectric constant $\left(\varepsilon_{1}\right)$ of $\mathrm{TiO}_{2}$ particles are 2.493 and 40-60, respectively. The UV adsorptive frequency is given as $v_{\mathrm{c}}=3 \times 10^{15} \mathrm{~s}^{-1}$. The Boltzmann and the Planck's constants are $\mathrm{B}=1.381 \times 10^{-23} \mathrm{~J} / \mathrm{K}$ and $\mathrm{h}=6.626 \times 10^{-34}$ J.s., respectively. With an absolute ambient temperature $\mathrm{T}$, the Hamaker constant $\mathrm{A}$ is calculated from Equation (6) to be $A=3.727 \times 10^{-19} \mathrm{~J}$. The Young's modulus E, the Poisson ratio $v$ and the particle yield stress $\sigma_{y}$ of Equations (13) and (15) are obtained from Shackelford and Alexander (2000), where $\mathrm{E}=282.76 \times 10^{9}(\mathrm{~Pa}), \quad v=0.28$ and $\sigma_{\mathrm{y}}=6.89 \times 10^{7}(\mathrm{~Pa})$. The distance between particle surfaces $\mathrm{z}$ is taken as $4 \times 10^{-10} \mathrm{~m}$, according to Krupp (1967).

Figures 4 and 5 illustrate the values of the plastic, elastic and van der Waals forces for $\mathrm{T}_{\mathrm{i}} \mathrm{O}_{2}$ particle of radius $\mathrm{R}=102 \mathrm{~nm}$. In addition to the variation of the three forces with respect to the particle radius of the $\mathrm{T}_{\mathrm{i}} \mathrm{O}_{2}$ powder, the calculation is extended to particle radii below and above $102 \mathrm{~nm}$, as shown in Figures 4 and 5. Note that for $\mathrm{R}=102 \mathrm{~nm}$ the plastic and van der Waals forces are identical. However, the elastic force appears to be insignificant. It was also noted that the elastic force remains unimportant compared to the van der Waals force according to the variation of the particle radius. These results show that the plastic and the van der Waals forces have the same effect on the $\mathrm{T}_{\mathrm{i}} \mathrm{O}_{2}$ powder for $\mathrm{d}_{\mathrm{p}}=204 \mathrm{~nm}$. However, for particle size greater than $300 \mathrm{~nm}$, the plastic force is unimportant than the van der Waals force. This behavior can be explained by the reduction of the aeration rate (porosity) in the solid structure in addition to the cohesion of particles with larger sizes. We think that the deformation of the solid structure is controlled by the plastic force. This can be explained by the closeness of the contact area, leading to an increase of the solid fraction.

We can think that the same behavior can occur during the consolidation test of the $\mathrm{TiO}_{2}$ powder structure. The particle-particle interactions are controlled by the plastic forces. Figure 3 shows that $\sigma_{p}$ increases (an increase of the external force) with the solid fraction $(1-\varepsilon)$, reflecting the reduction of the porous volume of the packed bed and the closeness of the particles areas. This behavior indicates that the plastic force becomes significant for the very cohesive powders (nanometric powders), but under consolidation. This phenomenon can explain the fact that the plastic deformation is important when the external force is applied on the solid structure and not on the porous volume of the packed bed.

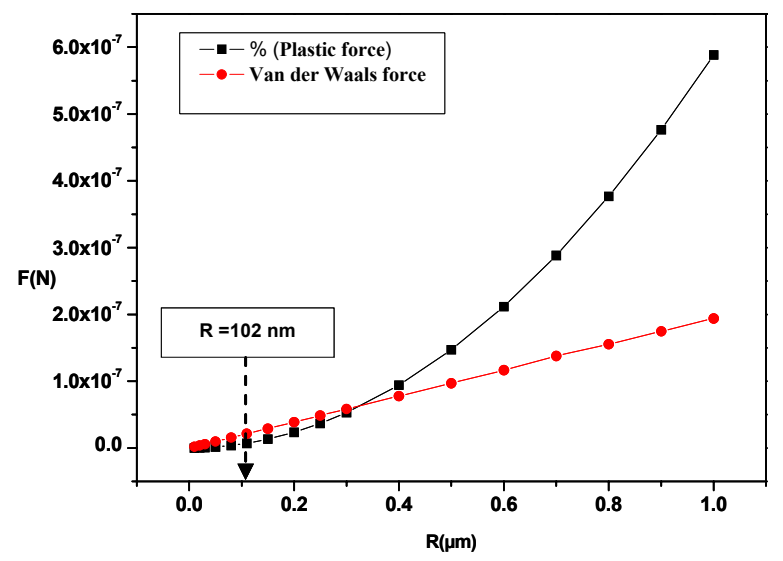

Figure 4: Comparison of plastic and van der Waals forces for $\mathrm{T}_{\mathrm{i}} \mathrm{O}_{2}$ particles.

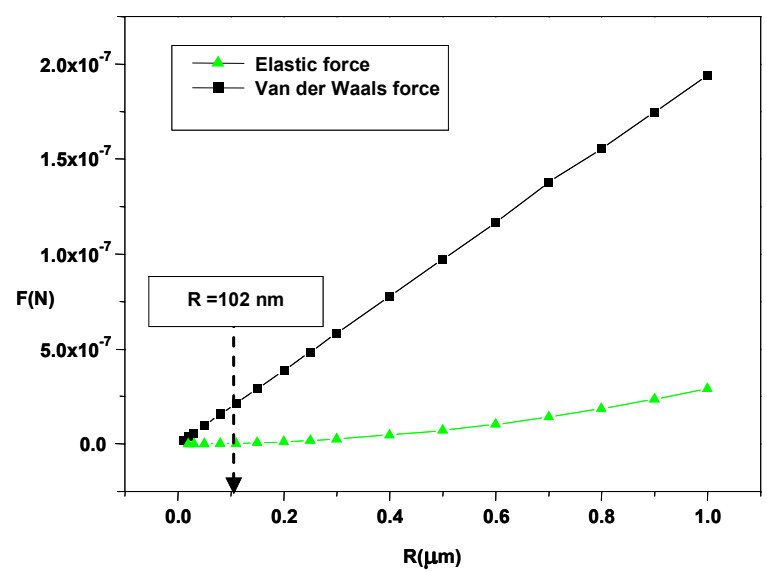

Figure 5: Comparison of elastic and van der Waals forces for $\mathrm{T}_{\mathrm{i}} \mathrm{O}_{2}$ particles.

\section{CONCLUSION}

This study shows the complexity of the cohesive powders and the evolution of the degree of cohesion under external forces. This work does not claim to answer all the questions, but tries to bring new elements concerning the role of each interaction force (van der Waals, elastic and plastic) on the evolution of the solid structure. 
The results confirm that van der Waals forces are the real cause of cohesion between particles (without consolidation effect) when the size of the particles is less than $300 \mathrm{~nm}$, causing a great interaction between the surfaces of the particles. The plastic deformation is engendered during the application of external forces (test of consolidation). This plastic deformation leads to the basis for the great cohesion force.

The same behavior is also noted for particle sizes greater than $300 \mathrm{~nm}$. Thus, there is a correlation between the deformation of the solid structure and the area of contact. The present case study illustrates the importance of the distinction between the behavior of the micronic and nanometric powders according to external forces.

These results are valid for spherical and smoother powder. Further investigations are required to compare and recalculate the three forces by changing the surface state of the powders. The literature (Fatah, 2009, Zhou et al. 2003) shows that the large amplitude of the asperities on the surface of particles tends to reduce the interaction forces due to the reduction of the area of contact.

\section{NOMENCLATURE}

$\begin{array}{ll}\text { A } & \text { Hamaker constant } \\ \mathrm{C}_{\mathrm{u}} & \text { Index of uniformity } \\ \mathrm{B} & \text { Boltzmann's constant } \\ \mathrm{D} & \text { Reduced diameter } \\ \mathrm{di} & \text { Average diameter in class i } \\ \mathrm{d}_{\mathrm{p}} & \text { Mean particle diameter } \\ \mathrm{E} & \text { Young's modulus } \\ \mathrm{F} & \text { Force } \\ \mathrm{F}_{\text {elastic }} & \text { Elastic force } \\ \mathrm{F}_{\mathrm{N}} & \begin{array}{l}\text { Applied force on the powder } \\ \text { structure }\end{array} \\ \mathrm{F}_{\text {plastic }} & \begin{array}{l}\text { Plastic force } \\ \mathrm{F}_{\mathrm{vdw}}\end{array} \\ \mathrm{h} & \text { van der Waals force } \\ \mathrm{K} & \begin{array}{l}\text { Planck's constant } \\ \text { Function of Poisson's ratio }\end{array} \\ \mathrm{M} & \text { and Young's modulus } \\ & \begin{array}{l}\text { Mass of the packed bed of } \\ \text { particles }\end{array} \\ \mathrm{Ni} & \text { Number of particles in class } \mathrm{i} \\ \mathrm{N}_{1} & \begin{array}{l}\text { Index of refraction of } \\ \text { particles }\end{array} \\ \mathrm{p} & \text { Normal pressure } \\ \mathrm{R} & \text { Particle radius } \\ \mathrm{S} & \text { Cross-sectional area of the } \\ & \text { glass piston } \\ \mathrm{s}_{\mathrm{p}} & \text { Surface of the particle }\end{array}$

$\begin{array}{llr}\mathrm{T} & \begin{array}{l}\text { Temperature } \\ \mathrm{V}_{\mathrm{t}}\end{array} & \begin{array}{l}\text { Total volume of the packed } \\ \text { bed of particles }\end{array} \\ \mathrm{W} & \begin{array}{l}\text { Total attractive energy } \\ \text { between two particles }\end{array} \\ \mathrm{Z} & \begin{array}{l}\text { Distance between the center } \\ \text { points of two molecules }\end{array} \\ \mathrm{z} & \begin{array}{l}\text { Distance between the two } \\ \text { particles }\end{array} & \mathrm{m} \\ \end{array}$

\section{Greek Letters}

$\begin{array}{llr}\varepsilon & \text { Bed voidage } & (-) \\ \varepsilon_{1} & \text { Dielectric constant of } & (-) \\ & \text { particles } & \\ \varphi & \text { Area of contact between two } & \mathrm{m}^{2} \\ & \text { particles } & \mathrm{kg} \cdot \mathrm{m}^{-3} \\ \rho_{\mathrm{p}} & \text { Particle density } & \mathrm{s}^{-1} \\ v_{\mathrm{c}} & \text { UV absorption frequency } & \mathrm{Pa} \\ \sigma & \text { Normal stress } & \mathrm{Pa} \\ \sigma_{\mathrm{p}} & \text { Normal stress interaction } & \mathrm{Pa} \\ & \text { particle-particle } & \text { Yield stress } \\ \sigma_{\mathrm{y}} & \text { Poisson's ratio } & (-) \\ v & \text { Pas }\end{array}$

\section{ACKNOWLEDGEMENTS}

The authors gratefully acknowledge the financial support from the Universite Ibn-Khaldoun de Tiaret and other support received from the Unite de Catalyse et de Chimie du Solide de Lille for this research.

\section{REFERENCES}

Bradley, R. S., The cohesive force between solid surfaces and the surface energy of solids. Phil. Mag., 13, p. 853-862 (1932).

Castellanos, A., The relationship between attractive interparticle forces and bulk behavior in dry and unchanged fine powders. Adv. Phys., No. 54, p. 263 (2005).

Christenson, H. K., Surface deformation in direct force measurements. Langmuir American Chemical Society, 12, p. 1404-1405 (1996).

Fatah, N., Study and comparison of micronic and nanometric powders: Analysis of physical, flow and interparticle properties of powders. Powder Technology, 190, p. 41-47 (2009).

Fichman, M., Pnueli, D., Sufficient conditions for small particles to hold together because of 
adhesion. Trans ASME Journal Appl. Mech., 52, p. 105-108 (1985).

Geldart, D., Types of gas fluidisation. Powder Technology 7, p. 285-292 (1973).

Götzinger, M., Peukert, W., Dispersive forces of particle-surface interaction: direct AFM measurements and modelling. Powder Technology Journal, 130, p. 102-109 (2003).

Hamaker, H. C., The London-Van der Waals Attraction Between Spherical Particles. Physica IV, No. 10, p. 1058 (1937).

Hertz, H., On Contact Between Elastic Bodies. Gesammelte Werke 1, Leipzig, Germany (1985).

Israelachvili, J. N., Intermolecular and Surface Forces. Academic Press, London (1991).

Johnson, K. L., Kendall, K., Roberts, A. D., Surface energy and contact of elastic solids. Proc. R. Soc., London Ser A, 324, p. 301-313 (1971).

Krupp, H., Particle Adhesion - Theory and Experiment. Adv. Coll. Interf. Sci., 1, p. 111-239 (1967).

London, F., The general theory of molecular forces. Transactions of the Faraday Society 33, p. 8-26 (1937).

Molerus, O., Theory of yield cohesive powders. Powder Technology, 12, p. 259-275 (1975).

Moreno-Antanasio, R., Antony, S. J., Ghadiri, M., Analysis of flowability of cohesive powders using distinct element method. Powder Technology, 158, p. 51-57 (2005).

Medhe, M., Pitchumani, B., Tomas, J., Flow characterization of fine powders using material characteristic parameters. Advanced Powder Technology, 16, No. 02, p.123-135 (2005).

Nakagaki, M., Sunada, H., Theoretical studies on structures of sedimentation bed of spherical particles. Yakugaku Zasshi, 88, p. 651 (1968).
Perry, R. H., Green, D., Perry's Chemical Engineers' Handbook $6^{\text {th }}$ ed. McGraw Hill (1984).

Quintanilla, M. A. S., Castellanos, A., Valverde, J. M., Correlation between bulk stresses and interparticle contact forces in fine powders. Phys Rev., p. 1-9 (2001).

Quintanilla, M. A. S., Valverde, J. M., Castellanos, A., Adhesion force between fine particles with controlled surface properties. AIChE, Vol. 52, n. 5, p. 1715-1728 (2006).

Rumpf, H., Agglomeration, in: W. A. Knepper (Ed.). Wiley, New York, p. 379 (1962).

Schlosser, F., Eléments de mécanique des sols. Presses de l'école National des Ponts et Chaussées, 26 (1988).

Shackelford, J. F., Alexander, W., CRC Materials Science and Engineering Handbook. Third Edition (2000).

Tabor, D., The Hardness of Metal. Oxford University Press (1951).

Turki, D., Fatah, N., Behavior and fluidization of the cohesive powders: Agglomerates sizes approach. Braz. J. Chem. Eng., 25, (4), p. 697-711 (2008).

Valverde, J. M., Castellanos, A., Compaction of fine powders from fluidized agglomerates to primary particles. Granular Matter, No. 9, p. 19-24 (2007).

Vermeer, P. A., Diebels, S., Ehlers, W., Hermann, H. J., Luding, S., Ramm, E., Continuous and discontinuous modelling of cohesive frictional materials. Berlin Springer, p. 143-148 (2001).

Xie, H. Y., The role of interparticle forces in the fluidization of fine particles, Powder Technology, 94, p. 99-108 (1997).

Zhou, H., Götzinger, M., Peukert, W., The influence of particle charge and roughness on particle- substrate adhesion, Powder Technology, 135-136, p. 82-91 (2003). 